УДК 616.14-007.64:618.3-06]-089

DOI 10.11603/2414-4533.2021.2.12296

(ОВ. М. АНТОНЮК-КИСІЛЬ, І. Я. ДЗЮБАНОВСЬКИЙ², М. І. ГЕРАСИМЮК

КнП “Обласний перинатальний центр” Рівненської обласної ради ${ }^{1}$

Тернопільський національний медичний університет імені І. Я. Горбачевського МОЗ України²

Тернопільська університетська лікарня ${ }^{3}$

\title{
Імплементація програми "fast track surgery" в хірургічному лікуванні первинного хронічного захворювання вен під час вагітності
}

\begin{abstract}
Мета роботи: підвищення безпеки та ефективності відкритого мініінвазивного хірургічного лікування первинного, прогресуючого варикозного розширення вен нижніх кінцівок, промежини, пахового каналу та зовнішніх статевих органів та їх поєднаних форм під час вагітності на основі принципів “fast track surgery”.

Матеріали і методи. У період із II кварталу 2015 року до I кварталу 2020 року на базі відділення екстрагенітальної патології КНП “Обласний перинатальний центр” Рівненської обласної ради обстежено та хірургічно проліковано 840 вагітних у другому-третьому триместрі з різними формами первинного хронічного захворювання вен нижніх кінцівок, промежини, пахового каналу та зовнішніх статевих органів та їх поєднаних форм. У хірургічному лікуванні використовували метод селективної мініфлебектомії - ASVAL, гемодинамічний метод - CHIVA в різних варіантах та поєднаннях.

Результати досліджень та їх обговорення. Оптимізовано мультидисциплінарну програму в периопераційному періоді. Запропонована в периопераційному періоді мультидисциплінарна програма “fast track surgery” дала можливість забезпечити у 89,29 \% випадків пологів природним шляхом без кровотеч та зменшити число тромботичних ускладнень у 2 рази.
\end{abstract}

Ключові слова: ERAS; вагітність; первинне хронічне захворювання вен.

Постановка проблеми і аналіз останніх досліджень та публікацій. Посилене відновлення після хірургічного втручання (ERAS) вперше було введено Келетом в 1997 році, щоб зменшити тривалість перебування в лікарні при відкритих сигмоподібнихих резекціях. У Китаї перший конгрес ERAS був створений у 2015 році, і з тих пір серія консенсусів китайських експертів була опублікована щодо цієї теми.

Сьогодні ERAS “проник” в широкий спектр хірургічних спеціальностей, і в цей період експерти $з$ усього світу публікували та оновлювали різні рекомендації. Незважаючи на те, що протоколи ERAS успішно впроваджені в багатьох суб' єктах та установах, використання ERAS в акушерстві відстає. Лише у 2018 році товариство ERAS опублікувало рекомендації щодо кесаревого розтину і на сьогодні відповідні дані в літературі обмежені [2].

Протокол пришвидшеного відновлення після різних хірургічних операцій (Enhanced recovery after surgery (ERAS)) в багатьох розвинених країнах світу вже давно імплементований. Проте в закордонних працях найбільше уваги приділяється принципам “fast track surgery” після проведених кесарських розтинів і розпрацьовані основні аспекти периопераційної підготовки вагітної жінки $[1,3]$. Втім для інших типів операційних втручань у вагітних немає розроблених чітких протоколів ERAS [4, 5].

На відміну від основ протоколу ERAS, у невагітних жінок під час вагітності дані протоколи мають охоплювати значно ширші горизонти, врахо- вувати не тільки особливості жіночого організму, а й вплив периопераційних чинників на плід.

Оскільки більшість акушерських пацієнтів молоді та здорові, вони можуть швидко одужати та мати мотивацію повернутися до нормального стану функціонування для догляду за дитиною, а посилене відновлення може принести користь системі охорони здоров'я, зменшивши витрати дефіцитних медичних ресурсів та зменшивши загальну вартість медичного обслуговування.

Докази американських фахівців вказують, що протоколи ERAS можуть допомогти зменшити тривалість перебування в лікарні на 7,8 \% або 4,86 год загалом і зменшити загальну післяопераційну вартість на 8,4 \% або 642,85 доларів на пацієнта загалом.

На сьогодні у всіх розвинених країнах протокол “fast track surgery" базується на ефективній телекомунікаційній системі зв’язку пацієнта та лікаря для плавного відновлення та запобігання будь-яким післяопераційним ускладненням. Технологічні досягнення у формі телемедицини доповнюють маркери моніторингу за станом пацієнта в амбулаторних умовах.

Мета роботи: підвищення безпеки та ефективності відкритого мініінвазивного хірургічного лікування первинного, прогресуючого варикозного розширення вен нижніх кінцівок, промежини, пахового каналу та зовнішніх статевих органів та їх поєднаних форм під час вагітності на основі принципів "fast track surgery". 
Матеріали і методи. У період із II кварталу 2015 року до I кварталу 2020 року на базі відділення екстрагенітальної патології КНП “Обласний перинатальний центр” Рівненської обласної ради обстежено та хірургічно проліковано 840 вагітних в другому-третьому триместрі з різними формами первинного хіронічного захворювання вен нижніх кінцівок, промежини, пахового каналу та зовнішніх статевих органів та їх поєднаних форм. У хірургічному лікуванні використовували метод селективної мініфлебектомії - ASVAL, гемодинамічний метод - CHIVA в різних варіантах та поєднаннях. Структура операційних втручань наведена в таблиці 1.

Таблиця 1. Розподіл вагітних за типом операційного втручання (n=840)

\begin{tabular}{|c|c|c|}
\hline Тип варикозного процесу & Тип операцій & Абс. (\%) \\
\hline \multicolumn{3}{|c|}{ Типова форма первинного хронічного захворювання вен } \\
\hline Низхідна форма у басейні сафенних вен & $\begin{array}{l}\text { Тип CHIVA +видалення варикозних конгломератів } \\
\text { відповідно до методики мініфлебектомії за } \\
\text { Мюллером в одну сесію }\end{array}$ & $387(46,07)$ \\
\hline Висхідна форма басейну сафенних вен & $\begin{array}{l}\text { Поєднання тип CHIVA + тип ASVAL+ видалення } \\
\text { варикозних конгломератів відповідно до методики } \\
\text { мініфлебектомії за Мюллером в одну сесію }\end{array}$ & $167(19,88)$ \\
\hline \multicolumn{3}{|c|}{ Атипова форма первинного хронічного захворювання вен } \\
\hline $\begin{array}{l}\text { Басейну несафенних вен (варикозне } \\
\text { расширення вен пахового каналу з їхнім } \\
\text { переходом на зовнішні статеві органи і } \\
\text { нижні кінцівки }\end{array}$ & $\begin{array}{l}\text { Перев’язування вен у ділянці зовнішнього } \\
\text { пахового кільця шляхом накладання 2-3 } \\
\text { лігатур обшиваням без видалення варикозних } \\
\text { конгломератів із статевих губ + видаленням } \\
\text { варикозних конгломератів на нижніх кінцівках } \\
\text { відповідно до методики мініфлебектомії за } \\
\text { Мюлером в одну сесію }\end{array}$ & $98(11,67)$ \\
\hline \multicolumn{3}{|c|}{ Поєднана форма } \\
\hline $\begin{array}{l}\text { Поєднання нисхідного басейну сафенних } \\
\text { вен із варикозним разширенням вен у } \\
\text { басейні несафенних вен }\end{array}$ & $\begin{array}{l}\text { Тип CHIVA + перев’язування вен у ділянці } \\
\text { зовнішнього пахового кільця шляхом накладання } \\
\text { 2-3 лігатур обшиванням без видалення } \\
\text { варикозних конгломератів із статевих губ + } \\
\text { видаленням варикозних конгломератів на нижніх } \\
\text { кінцівках відповідно до методики мініфлебектомії } \\
\text { за Мюлером в одну сесію }\end{array}$ & $188(22,38)$ \\
\hline
\end{tabular}

У всіх вагітних використано різновид місцевої анестезії (тумінесцентне знеболення) в поєднанні з відволікальною терапією. “Класичну” премедикацію не виконували в жодному випадку для запобігання розвитку акушерських ускладнень, зумовлених наркотичними середниками.

Результати досліджень та їх обговорення. Разом з акушером-гінекологом розроблено персоналізовану підготовку та показання до безпечного як для вагітної, так і плода відкритого планового операційного втручання розприділивши на етапи, з огляду на програму “fast track surgery” з причини прогресування первинної варикозної хвороби пахового каналу i/або нижніх кінцівок та промежини. Мультидициплінарна програма включала 3 етапи: передопераційний, інтраопераційний та післяопераційний (табл. 2-4).

Розроблені передопераційні елементи, засновані на елементах доказової медицини, представлено в таблиці 2. 
Таблиця 2. Передопераційні елементи протоколу ERAS

\begin{tabular}{|c|c|c|c|c|}
\hline Рекомендація & Дія & Коментар & $\begin{array}{c}\text { Сила } \\
\text { рекомендації }\end{array}$ & $\begin{array}{c}\text { Рівень } \\
\text { доказовості }\end{array}$ \\
\hline $\begin{array}{l}\text { Обмеження } \\
\text { інтервалів } \\
\text { голодування }\end{array}$ & $\begin{array}{l}\text { Обмеження вживання } \\
\text { води та їжі за } 1 \text { годину до } \\
\text { операції }\end{array}$ & $\begin{array}{l}\text { Одночасно обмежує } \\
\text { гіповолемію, } \\
\text { метаболічний стрес та } \\
\text { кетозацидоз }\end{array}$ & Клас II b & C-EO \\
\hline $\begin{array}{l}\text { Вживання } \\
\text { збагаченої } \\
\text { вуглеводами } \\
\text { рідини }\end{array}$ & $\begin{array}{l}\text { Напій збагачений } \\
\text { вуглеводами } \\
\text { за } 2 \text { год до операції } \\
\text { (обмеження для } \\
\text { вагітних із ЦД) }\end{array}$ & $\begin{array}{l}\text { Знижує материнську } \\
\text { гіпоглікемію та } \\
\text { метаболічний стрес }\end{array}$ & Клас II b & C-EO \\
\hline $\begin{array}{l}\text { Навчання } \\
\text { пацієнта }\end{array}$ & $\begin{array}{l}\text { Безпосередній контакт із } \\
\text { хворими через } \\
\text { телефонний зв’язок для } \\
\text { роз’яснення пацієнтці } \\
\text { основної мети протоколу } \\
\text { ERAS }\end{array}$ & $\begin{array}{l}\text { Метою навчання пацієнтів } \\
\text { ЕRAС є встановлення } \\
\text { очікувань та розширення } \\
\text { можливостей } \\
\text { пацієнта брати більш } \\
\text { повну участь у процесі } \\
\text { догляду та відновлення }\end{array}$ & Клас II b & C-NR \\
\hline $\begin{array}{l}\text { Лактація } \\
\text { (навчання та } \\
\text { підготовка } \\
\text { до годування } \\
\text { грудним } \\
\text { молоком) }\end{array}$ & $\begin{array}{l}\text { Структуровані } \\
\text { пренатальні класи та } \\
\text { книги; групи підтримки } \\
\text { грудного вигодовування } \\
\text { та / або } \\
\text { консультант із лактації } \\
\text { після виписування }\end{array}$ & $\begin{array}{l}\text { Раннє грудне } \\
\text { вигодовування покращує } \\
\text { стан новонароджених, } \\
\text { включно сприяє } \\
\text { емоційній прихильності, } \\
\text { зменшує } \\
\text { інфекційні ускладнення }\end{array}$ & Клас II а & B-R \\
\hline $\begin{array}{l}\text { Оптимізація } \\
\text { рівня } \\
\text { гемоглобіну }\end{array}$ & $\begin{array}{l}\text { Всі вагітні жінки повинні } \\
\text { пройти обстеження на } \\
\text { виявлення анемії }\end{array}$ & $\begin{array}{l}\text { Акушерською командою } \\
\text { впродовж } \\
\text { пренатальних візитів } \\
\text { залучати пацієнтку до } \\
\text { розуміння важливості } \\
\text { оптимізації рівня } \\
\text { гемоглобіну; } \\
\text { належним чином лікувати } \\
\text { пренатальну анемію }\end{array}$ & Клас II а & B-R \\
\hline
\end{tabular}

Таблиця 3. Інтраопераційні елементи протоколу ERAS

\begin{tabular}{||c|l|l|c|c||}
\hline \multicolumn{1}{||c|}{ Рекомендація } & \multicolumn{1}{|c|}{ Дія } & \multicolumn{1}{|c||}{ Коментар } & $\begin{array}{c}\text { Сила } \\
\text { рекомендації }\end{array}$ & $\begin{array}{c}\text { Рівень } \\
\text { доказовості }\end{array}$ \\
\hline 1 & 2 & 3 & 4 & Клас I \\
\hline $\begin{array}{l}\text { Підтримання } \\
\text { нормотермії }\end{array}$ & $\begin{array}{l}\text { Підтримання } \\
\text { оптимальної } \\
\text { температури під час } \\
\text { проведення операції } \\
\text { на рівні 22-23 }{ }^{0} \mathrm{C}\end{array}$ & $\begin{array}{l}\text { Активне } \\
\text { підтримання } \\
\text { теплового режиму } \\
\text { включає контроль за } \\
\text { иого виконанням у } \\
\text { передопераційний, } \\
\text { операційний періоди }\end{array}$ & & С \\
\hline
\end{tabular}


Продовження табл. 3

\begin{tabular}{|c|c|c|c|c|}
\hline 1 & 2 & 3 & 4 & 5 \\
\hline $\begin{array}{l}\text { Оптимальний } \\
\text { контроль за тонусом } \\
\text { матки }\end{array}$ & $\begin{array}{l}\text { Досягнення та } \\
\text { підтримання } \\
\text { адекватного тонусу } \\
\text { матки і мінімізація } \\
\text { побічних ефектів }\end{array}$ & $\begin{array}{l}\text { Підтримка під час } \\
\text { проведення операції } \\
\text { заснована на } \\
\text { інтраопераційному } \\
\text { КТГ }\end{array}$ & Клас II & A \\
\hline $\begin{array}{l}\text { Внутрішньовенне } \\
\text { підтримання } \\
\text { гомеостазу }\end{array}$ & $\begin{array}{l}\text { Обмеження } \\
\text { введення рідин } \\
\text { внутрішньовенно до } \\
3 \text { літрів }\end{array}$ & $\begin{array}{l}\text { Активне введення } \\
\text { ізотонічних } \\
\text { середників під час } \\
\text { операції у вказаних } \\
\text { оптимальних об’ємах }\end{array}$ & Клас II а & C \\
\hline
\end{tabular}

Таблиця 4. Післяопераційні елементи протоколу ERAS

\begin{tabular}{|c|c|c|c|c|}
\hline Рекомендація & Дія & Коментар & $\begin{array}{c}\text { Сила } \\
\text { рекомендації }\end{array}$ & $\begin{array}{c}\text { Рівень } \\
\text { доказовості }\end{array}$ \\
\hline $\begin{array}{l}\text { Раннє } \\
\text { відновлення } \\
\text { ентерального } \\
\text { харчування }\end{array}$ & $\begin{array}{l}\text { Відновлення приймання } \\
\text { їжі до } \\
1 \text { години після } \\
\text { проведеного } \\
\text { хірургічного лікування }\end{array}$ & $\begin{array}{l}\text { Зменшує рівень } \\
\text { післяопераційного } \\
\text { стресу, зменшує ризик } \\
\text { післяопераційної нудоти } \\
\text { та блювання, } \\
\text { нормалізує } \\
\text { післяопераційний } \\
\text { метаболізм, покращує } \\
\text { чутливість до інсуліну }\end{array}$ & Клас II b & C-EO \\
\hline Рання мобілізація & $\begin{array}{l}\text { У терміни 0-8 годин } \\
\text { повне відновлення } \\
\text { рухової активності }\end{array}$ & $\begin{array}{l}\text { Активна профілактика } \\
\text { тромбоемболічних } \\
\text { процесів, гіпоксії плода }\end{array}$ & Клас I & B-NR \\
\hline $\begin{array}{l}\text { Сприяння } \\
\text { ранньому } \\
\text { виписуванню зі } \\
\text { стаціонару }\end{array}$ & $\begin{array}{l}\text { Стандартизування } \\
\text { плану пришвидшеного } \\
\text { виписування } 3 \\
\text { налагодженням } \\
\text { амбулаторного } \\
\text { контролю за перебігом } \\
\text { п/о періоду }\end{array}$ & $\begin{array}{l}\text { Активна співпраця } \\
\text { лікаря-хірурга } \\
\text { та акушера- } \\
\text { гінеколога в процесі } \\
\text { післяопераційної } \\
\text { комунікації з вагітною }\end{array}$ & Клас II b & C-EO \\
\hline $\begin{array}{l}\text { Сприяння } \\
\text { періоду } \\
\text { відпочинку }\end{array}$ & $\begin{array}{l}\text { Оптимізація режиму } \\
\text { сну та відпочинку }\end{array}$ & $\begin{array}{l}\text { Втома потенційно } \\
\text { негативно впливає на } \\
\text { когнітивні процеси, } \\
\text { рівень больового } \\
\text { синдрому, порушення } \\
\text { фетоплацентарного } \\
\text { комплексу }\end{array}$ & Клас II b & C-EO \\
\hline $\begin{array}{l}\text { Рівень } \\
\text { гемоглобіну }\end{array}$ & $\begin{array}{l}\text { Виявлення та корекція } \\
\text { анемії }\end{array}$ & $\begin{array}{l}\text { Контроль за рівнем } \\
\text { гемоглобіну в день } \\
\text { операції та перед } \\
\text { виписуванням }\end{array}$ & Клас I & A \\
\hline
\end{tabular}


Умови для виписування вагітної 3 акушерського стаціонару:

- стабільні показники гемодинаміки, які були до операційного втручання;

- біль відсутній або помірний, характерний для даного операційного втручання, не потребує знеболювальних;

- $з$ боку післяопераційної рани не має ознак кровотечі, гематом, некрозів країв рани, нагноєння;

- тонус матки в межах норми;

- серцебиття плода в нормі;

\section{СПИСОК ЛІТЕРАТУРИ}

1. Evaluation of the impact of enhanced recovery after surgery protocol implementation on maternal outcomes following elective cesarean delivery / A. M. Kleiman, C. A. Chisholm, A. J. Dixon [et al.] // International Journal of Obstetric Anesthesia. - 2020. 43. - P. 39-46.

2. Guidelines for postoperative care in cesarean delivery: Enhanced Recovery After Surgery (ERAS) Society recommendations (part 3) / G. A. Macones, A. B. Caughey, S. L. Wood [et al.] // American Journal of Obstetrics and Gynecology. - 2019. - Vol. 221 (3). - P. 247-e1.

3. Better late than never: why obstetricians must implement enhanced recovery after cesarean / A. F. Peahl, R. Smith,
- оцінка рухів дитини за суб’єктивною оцінкою вагітної без особливостей;

УЗД оцінка зон операційного втручання - відсутність патологічного кровотоку, підшкірних інфільтратів.

Висновок. Запропонована в периопераційному періоді мультидисциплінарна програма “fast track surgery” дала можливість забезпечити у 89,29 \% випадків пологів природним шляхом без кровотеч та зменшити число тромботичних ускладнень у 2 рази.

T. R. Johnson [et al.] // American Journal of Obstetrics and Gynecology, 2019. - Vol. 221 (2). - P. 117-121.

4. Pilkington L. Enhanced recovery after surgery (ERAS) in obstetrics in Royal Gwent Hospital / L. Pilkington, S. Curpad, S. Parveen // European Journal of Obstetrics and Gynecology and Reproductive Biology. - 2016. - Vol. 206. - P. 92.

5. Implementing a structured Enhanced Recovery After Surgery (ERAS) protocol reduces length of stay after abdominal hysterectomy / L. Wijk, K. Franzen, O. Ljungqvist, K. Nilsson // Acta Obstetricia et Gynecologica Scandinavica. - 2014. - Vol. 3 (8). - P. 749-756.

\section{REFERENCES}

1. Kleiman A.M., Chisholm C.A., Dixon A.J., Sariosek B.M., Thiele R.H., Hedrick T.L., ... \& Tiouririne M. (2020). Evaluation of the impact of enhanced recovery after surgery protocol implementation on maternal outcomes following elective cesarean delivery. International Journal of Obstetric Anesthesia, 43, 39-46.

2. Macones, G.A., Caughey, A.B., Wood, S.L., Wrench, I.J., Huang, J., Norman, M., ... \& Wilson, R. D. (2019). Guidelines for postoperative care in cesarean delivery: Enhanced Recovery After Surgery (ERAS) Society recommendations (part 3). American Journal of Obstetrics and Gynecology, 221 (3), 247-e1.

3. Peahl A.F., Smith R., Johnson T.R., Morgan D.M., \&

Pearlman M.D. (2019). Better late than never: why obstetricians must implement enhanced recovery after cesarean. American Journal of Obstetrics and Gynecology, 221 (2), 117-121.

4. Pilkington L., Curpad S., \& Parveen S. (2016). Enhanced recovery after surgery (ERAS) in obstetrics in Royal Gwent Hospital. European Journal of Obstetrics and Gynecology and Reproductive Biology, 206, 92.

5. Wijk L., Franzen K., Ljungqvist O., \& Nilsson K. (2014). Implementing a structured Enhanced Recovery After Surgery (ERAS) protocol reduces length of stay after abdominal hysterectomy. Acta Obstetricia et Gynecologica Scandinavica, 93 (8), 749-756.

Отримано 12.01.2021 


\title{
V. M. ANTONYK-KYSIL ${ }^{1}$, I. YA. DZIUBANOVSKYI², M. I. HERASYMIUK ${ }^{3}$
}

Regional Perinatal Center, Rivne Regional Council 1

I. Horbachevsky Ternopil National Medical University ${ }^{2}$

Ternopil University Hospital ${ }^{3}$

\section{IMPLEMENTATION OF THE FAST TRACK SURGERY PROGRAM IN THE SURGICAL TREATMENT OF PRIMARY CHRONIC VEIN DISEASE DURING PREGNANCY}

\begin{abstract}
The aim of the work: to increase the safety and effectiveness of open minimally invasive surgical treatment of primary, progressive varicose veins of the lower extremities, perineum, inguinal canal and external genitalia and their combined forms during pregnancy based on the principles of fast track surgery.

Materials and Methods. In the period from the second quarter of 2015 to the first quarter of 2020 on the basis of the Department of Extragenital Pathology "Regional Perinatal Center" Rivne Regional Council examined and surgically treated 840 pregnant women in the second and third trimester with various forms of primary chronic disease of the lower extremities, perineum, groin canal and external genitalia and their combined forms. The method of selective miniphlebectomy - ASVAL, hemodynamic method - CHIVA in different variants and combinations were used in surgical treatment.

Results and Discussion. The multidisciplinary program in the perioperative period was optimized. The multidisciplinary fast track surgery program proposed in the perioperative period made it possible to provide $89.29 \%$ of cases of natural childbirth without bleeding and reduce the number of thrombotic complications by 2 times.
\end{abstract}

Key words: ERAS; pregnancy; primary chronic venous disease.

\section{В. М. АНТОНЮК-КИСИЛЬํำ И. Я. ДЗЮБАНОВСКИЙ², М. И. ГЕРАСИМЮК}

КНП "Областной перинатальный центр" Ривненского областного совета ${ }^{1}$

Тернопольский национальный медицинский университет имени И. Я. Горбачевского МОз Украины²

Тернопольская университетская больница ${ }^{3}$

\section{ИМП.ЛЕМЕНТАЦИЯ ПРОГРАММЫ “FАSТ ТRАСК SURGЕRУ” В ХИРУРГИЧЕСКОМ ЛЕЧЕНИИ ПЕРВИЧНОГО ХРОНИЧЕСКОГО ЗАБОЛЕВАНИЯ ВЕН ВО ВРЕМЯ БЕРЕМЕННОСТИ}

\begin{abstract}
Цель работы: повышение безопасности и эффективности открытого миниинвазивного хирургического лечения первичного, прогрессирующего варикозного расширения вен нижних конечностей, промежности, пахового канала и наружных половых органов и их сочетанных форм во время беременности на основе принципов “fast track surgery”.

Материалы и методы. В период со II квартала 2015 году по I квартал 2020 года на базе отделения экстрагенитальной патологии КНП “Областной перинатальный центр” Ривненского областного совета обследовано и хирургически пролечено 840 беременных во втором-третьем триместре с различными формами первичного хронического заболевания вен нижних конечностей, промежности, паховой канала и наружных половых органов и их сочетанных форм. В хирургическом лечении использовали метод селективной минифлебэктомии - ASVAL, гемодинамический метод - CHIVA в различных вариантах и сочетаниях.

Результаты исследований и их обсуждение. Оптимизирована мультидисциплинарная программа в периоперационном периоде. Предложенная в периоперационном периоде мультидисциплинарная программа "fast track surgery” дала возможность обеспечить в 89,29 \% случаев родов естественным путем без кровотечений и уменьшить число тромботических осложнений в 2 раза.
\end{abstract}

Ключевые слова: ERAS; беременность; первичное хроническое заболевание вен. 